\title{
FUNDO DA EDUCAÇÃO BÁSICA EM PERSPECTIVA: HISTÓRIA PRESENTE E MOBILIZAÇÃO
}

\author{
Jean Mac Cole Tavares Santos ${ }^{1}$ \\ Universidade do Estado do Rio Grande do Norte - UERN
}

\section{RESUMO:}

Esta comunicação versa sobre o processo de constituição do Fundo de Manutenção e Desenvolvimento da Educação Básica e de Valorização dos Profissionais da Educação (FUNDEB). Apresenta, primeiro, os movimentos legais, desde as propostas elaboradas no Ministério da Educação até as principais alterações na Câmara e no Senado Federal. Mostra, depois, a mobilização dos movimentos docentes e da sociedade organizada através da APEOESP, do CNTE, da UNDIME, do CONSED e de outros, vendo as diversas exigências das organizações e as consequentes flexibilizações e os rebaixamentos das exigências iniciais em nome de um possível consenso pela educação. Atenta para o fato de o tema fazer parte da história recente da educação brasileira, sendo impossível prever, com certeza, os rumos dessa política. A proposta busca, ainda, pensar algumas das expectativas para a educação básica e, particularmente, para o ensino médio.

Palavras-chave: FUNDEB, História e financiamento da educação, Política e educação.

\section{FUND OF BASIC EDUCATION IN PERSPECTIVE: PRESENT HISTORY AND MOBILIZATION}

\begin{abstract}
:
This Communication focuses on the formation of Fundo de Manutenção e Desenvolvimento da Educação Básica e Valorização dos Profissionais da Educação (Fund for the Maintenance and Development of Basic Education - FUNDEB). It presents, first, the legal moves from the proposals prepared in the Education Ministry to major changes in the Chamber of Deputies and Senate. Shows after, the mobilization of teachers and society organized by APEOESP, CNTE, UNDIME, CONSED and others, seeing the different requirements of organizations and the resulting flexibilities and downgrades of initial requirements in the name of a possible consensus for education. Notes to the fact that the theme be part of the recent history of Brazilian education, one can not predict with certainty the direction that policy. The proposal seeks also think some of the expectations for basic education, and particularly to high school.
\end{abstract}

Keywords: FUNDEB, History and financing of education, policy and education

\section{Introdução}

No dia 06 de dezembro de 2006, a Câmara dos Deputados aprovou, em segundo turno, a Proposta de Emenda Constitucional (PEC), que cria o Fundo de Manutenção e Desenvolvimento da Educação Básica e de Valorização dos Profissionais da Educação (FUNDEB). Alguns dias depois, na tarde de 19 de dezembro de 2006, em sessão solene do Congresso Nacional, com a presença do ministro da educação, Fernando Haddad, o presidente do Senado, Renan Calheiros, declarou promulgada a Emenda Constitucional 53/2006, cujo texto final teve como base a PEC, enviada ao Congresso pelo MEC, em 14 
de Junho de 2005, ainda sob a direção do ministro da educação, Tarso Genro. Assim, a PEC do FUNDEB tramitou entre a Câmara e o Senado durante um ano e seis meses.

Mesmo com o fato de a implementação do FUNDEB fazer parte da história recente da educação brasileira, sendo impossível prever os rumos dessa política, vale pensar algumas questões sobre ele, já que se trata de uma reivindicação histórica dos trabalhadores em educação e que pretende beneficiar diretamente a educação básica. Claro que, primeiramente, é necessário atentar para as grandes questões de quem se debruça para pensar o contemporâneo: a questão da proximidade com o que está acontecendo, o envolvimento com os acontecimentos da época, a dispersão do local e do tempo presente, o ofuscamento de alguns fatos por outros, entre outros cuidados. Em suma, a história e o sujeito histórico podem se entrelaçar de tal forma que chegam a se confundir no meio do fato histórico.

Para LACOUTURE (2000), por exemplo, fazer história imediata é ser GeorgesJacques Danton levado ao cadafalso, falando ao povo de sua relação com a revolução e explicando o significado da sua morte. Tal postura militante, que serve para mostrar o envolvimento inevitável entre os acontecimentos e o historiador, mostra a dificuldade de contar algo de que estamos participando, em que estamos atuando conscientemente, inclusive para mudanças de rumos da história. Por isso, fazer história no calor dos acontecimentos é um desafio e um enfrentamento que exigem atenção redobrada.

Três pontos serão considerados: a mobilização da sociedade civil em torno da proposta do FUNDEB; a apresentação do fundo e sua regulamentação e as perspectivas de atendimento das demandas da educação básica e, em particular, do Ensino Médio, com as mudanças propostas pela nova lei.

\section{A mobilização}

Para o MEC, nas palavras de sua assessoria de comunicação, a proposta aprovada pela Câmara foi, desde sua elaboração, fruto de uma ampla discussão com a sociedade ${ }^{2}$. Esse Ministério promoveu cinco colóquios estaduais e dois nacionais, em 2004, com a participação de instituições, entidades educacionais e especialistas da área de educação e de finanças, para o debate e a apresentação de sugestões para a proposta do governo. Mesmo considerando que o amplo dito pelo MEC pode ser alocado em poucas linhas, é fácil constatar que uma parte significativa de entidades com uma história política em defesa da educação pôde intervir na aprovação do FUNDEB e pressionar para que isso acontecesse.

Exemplo disso são as articulações da APEOESP (Sindicato dos Professores do Ensino Oficial do Estado de São Paulo), principal sindicato de trabalhadores em educação do país e da CNTE (Confederação Nacional dos Trabalhadores em Educação), que congrega 35 entidades de trabalhadores em educação de todo o Brasil, inclusive a própria APEOESP, em defesa da aprovação do Fundo. Somado a essa exemplificação, surge o movimento "FUNDEB pra Valer!", liderado pela Campanha Nacional pelo Direito à Educação, criada em outubro de 1999, no contexto preparatório da Cúpula Mundial de Educação no Senegal (DAKAR/2000), por um grupo de organizações da sociedade civil brasileira, incluindo-se a UNDIME e o CONSED, de um lado, e o MST, a UNE e a UBES, de outro, reforçando a ideia de que o governo conseguiu reunir em torno da proposta um setor considerável da sociedade organizada ${ }^{3}$.

A seguir, vale conferir alguns posicionamentos dessas entidades/movimentos consideradas exemplificadoras da participação da sociedade civil na discussão e aprovação da Emenda à Constituição, elementos que as tornam coautoras do resultado final. 
O Sindicato dos Professores do Ensino Oficial do Estado de São Paulo, em 1999, quando o governador de São Paulo era Mário Covas, e o Presidente da República, Fernando Henrique, lançou uma campanha em seu jornal pela aprovação da proposta de FUNDEB enviada à Câmara pela bancada do Partido dos Trabalhadores ${ }^{4}$. Desde essa época que consta na pauta de mobilização do Sindicato a reivindicação pela implantação de um fundo que atenda a toda a educação básica, e não, somente ao Ensino Fundamental. A mobilização foi intensificada posteriormente à vitória de Lula, em 2002, e virou uma campanha permanente, com o envio da proposta do governo ao Congresso, como se pode verificar no Jornal da APEOESP e nos boletins eletrônicos denominados $F A X$, ambos disponíveis no site da entidade (www.apeoesp.org.br/FUNDEB).

O Jornal da APEOESP, de junho de 2006 (número 269), traz a seguinte manchete: "FUNDEB: Luta é no Senado". O texto anuncia que uma caravana do sindicato participou de uma vigília organizada pela CNTE para reivindicar que o Senado desse prosseguimento imediato à proposta de emenda que cria o fundo. Segundo o artigo do jornal, a matéria teve que voltar para o plenário, devido ao fato de a Comissão de Constituição e Justiça (CCJ) do próprio Senado ter aprovado o texto do FUNDEB, com destaque para algumas emendas, "como a que muda o prazo para a União aplicar $10 \%$ do total de recursos no plano". Segundo a notícia,

A aprovação [dos destaques na CCJ] é resultado da pressão de milhares de professores - entre eles, representantes da APEOESP - que foram a Brasília em caravanas durante a VII Semana Nacional em Defesa e Promoção da Escola Pública, organizada pela CNTE na última semana de abril. A mobilização deve continuar para que o FUNDEB seja aprovado também no [plenário do] Senado Federal.

No dia 06/07/2006, no informativo eletrônico da APEOESP, Fax nº 38, a manchete é ainda mais expressiva: "Vitória dos trabalhadores em educação: Senado aprova FUNDEB". O texto apresenta a provação como

mais uma vitória dos trabalhadores em Educação. Os senadores aprovaram, na noite de terça-feira, 4, em dois turnos de votação, o substitutivo da Comissão de Constituição, Justiça e Cidadania à proposta de emenda à Constituição (PEC 9/2006), que cria o Fundo de Manutenção e Desenvolvimento da Educação Básica e de Valorização dos Profissionais de Educação (FUNDEB). Na primeira votação, os 57 senadores presentes à sessão aprovaram a PEC por unanimidade; no segundo turno, registraram-se 50 votos favoráveis e uma abstenção.

No entender da direção do sindicato paulista, com a aprovação do Senado ao substitutivo aprovado anteriormente pela Comissão de Constituição e Justiça, consolida-se a vitória da pressão exercida pela caravana de educadores a Brasília. A atenção, agora, deveria voltar-se, mais uma vez, para a Câmara dos Deputados, já que a PEC necessitava tramitar novamente para que os deputados pudessem discutir as modificações feitas.

A mobilização em prol da aprovação e do aprimoramento do FUNDEB também é acompanhada pelo site da Confederação Nacional dos Trabalhadores em Educação ${ }^{5}$, pelo Jornal Mural do CNTE e pelos boletins informativos CNTEinforma ${ }^{6}$.

Tanto quanto a APEOESP, a CNTE acompanhou, passo a passo, toda a elaboração e o trâmite da PEC do FUNDEB na Câmara e no Senado. No site da CNTE, há informações, quase em tempo real, dos momentos que atravessavam a proposta e suas 
dificuldades de aprovação, dando destaque para as reuniões da presidenta da entidade com os presidentes da Câmara de deputados e do Senado, para exigir rapidez na tramitação da matéria, além de suas participações em audiência pública com o ministro da educação. No entanto, seleciona-se aqui, como marca da CNTE na mobilização pelo FUNDEB, uma carta aberta aos parlamentares, lançada logo após a aprovação da PEC no Senado.

\section{CARTA DA CNTE AOS PARLAMENTARES PELA APROVAÇ̃̃O DO FUNDEB}

Senhor(a) Deputado(a):

Tendo em vista a aprovação da PEC 009/06 no Senado Federal, a qual visa instituir o FUNDEB, o retorno da matéria à Câmara dos Deputados e considerando:

1. que o Fundo do Ensino Fundamental - FUNDEF - expira no fim desse ano de 2006;

2. que a lei de regulamentação do FUNDEB precisa ser aprovada ainda nesse exercício, sob pena de inviabilizar a implementação do Fundo no início de 2007, com todos os entes federados devidamente preparados para operacioná-lo;

3. que a regulamentação do FUNDEB envolve interesses diversificados de estados $e$ municípios e certamente exigirá uma ampla negociação em prazo exíguo de tempo, em função do período eleitoral que limitará o funcionamento do Congresso Nacional;

4. que o FUNDEB é, atualmente, o único instrumento de política de financiamento educacional capaz de evitar um colapso no sistema de educação básica brasileiro, tendo em vista a crescente demanda das matrículas nas etapas não atendidas pelo atual fundo do ensino fundamental (educação infantil, ensino médio e educação de jovens e adultos) e a impossibilidade da atual legislação em direcionar recursos para as mesmas;

5. que os(as) parlamentares já aprovaram o FUNDEB, quase que por unanimidade, atendendo a reivindicação dos movimentos sociais, em especial da área educacional, como a CNTE, UBES, UNE, Campanha pelo Direito à Educação.

Vimos solicitar a Vossa Excelência o total empenho para a aprovação URGENTE da Proposta de Emenda Constitucional do FUNDEB, haja vista que a PEC contou com enorme consenso em sua primeira tramitação entre os/as deputados/as, como também no retorno a CCJ dessa Casa.

Certos de contar com sua posição favorável a essa reivindicação, subscrevemo-nos.

Atenciosamente,

Raquel Felau Guisoni

Presidenta, em exercício, da CNTE.

A Carta traz duas preocupações explícitas e uma implícita, que coloca em xeque tanto a aprovação quanto a implementação do FUNDEB. Explicitamente, a CNTE demonstrou preocupação com o fato de a Lei do FUNDEF estar chegando ao fim sem que nenhuma outra fosse colocada para substituí-la. Tal imbróglio poderia deixar a educação, no caso, o Ensino Fundamental, sem recurso previsto em lei. A segunda preocupação, diretamente relacionada com a primeira, é de que, para o FUNDEB entrar em vigor já no ano de 2007, cobrindo a brecha deixada pela Lei do FUNDEF, no financiamento do Ensino Fundamental e, ainda, ampliando para outras modalidades de ensino, era necessário que a aprovação do Fundo se desse de maneira rápida. Caso o FUNDEB fosse protelado por muito tempo, faltariam as condições objetivas para que sua regulamentação fosse feita de maneira que Estados e municípios pudessem se preparar para pô-lo em prática.

Implicitamente, a preocupação da CNTE é com a paralisação das atividades legislativas, devido à proximidade das eleições. Ora, entre julho e setembro de 2006, a maioria esmagadora dos deputados federais estava em atividades eleitorais, fosse 
almejando a renovação do mandato ou pleiteando outro cargo. Da mesma forma, no mínimo, um terço do Senado estava passando pela mesma situação. Entre a atividade legislativa e a caça aos votos, os nobres representantes do povo, como se constatou mais adiante, optaram pela busca de manutenção do mandato.

Somado a isso, tem ainda o fato de o presidente Lula tentar a reeleição e as disputas para governador em todos os estados brasileiros. A eleição de 2006 ficou polarizada entre o PSDB (Partido da Social Democracia Brasileira) e o PT (Partido dos Trabalhadores), e a aprovação do FUNDEB daria um empurrão no discurso do Partido dos Trabalhadores. Assim, ficava cada vez mais evidente a influência no processo eleitoral, numa votação de tamanha importância. O FUNDEB, claro, era também uma disputa eleitoral, tanto por parte dos aliados do governo federal que, impreterivelmente, sairia como o grande articulador da proposta, quanto por resistência da oposição, que não queria propiciar tamanha vantagem ao adversário em um momento tão acirrado eleitoralmente.

De resto, todos estavam envolvidos, direta ou indiretamente, no processo eleitoral, tanto como candidatos quanto como militantes e apoiadores de um ou de outro candidato. Prova disso é que a professora Juçara Dutra Vieira pediu afastamento temporário da presidência da CNTE para se candidatar na chapa que disputou a senatoria pelo PT do Rio Grande do $\mathrm{Sul}^{7}$. Assim, a CNTE tinha razão em se preocupar com a possibilidade de que o processo eleitoral pudesse atrapalhar, como de fato atrasou, a aprovação do FUNDEB.

A Campanha Nacional pelo Direito à Educação foi o movimento da sociedade civil que mais pode sintetizar a ação participativa na discussão, na intervenção e na celebração do resultado do FUNDEB. Todas as notícias da PEC, as mobilizações da sociedade civil e dos parlamentares, as reivindicações por alterações da Emenda, as propostas de alterações que foram derrotadas e, claro, as celebrações pelos resultados na Câmara e no Senado favoráveis à medida podiam ser acompanhadas pelo site da Campanha ${ }^{8}$.

Desde os primeiros momentos em que a Proposta de Emenda Constitucional foi enviada ao Congresso pelo governo, que a Campanha reclamava a necessidade de alterar a proposta inicial. Para isso, foi criada uma ação designada "FUNDEB PRA VALER! Direito à educação começa no berço e é pra toda vida". A principal reivindicação da ação era a inclusão das creches na proposta de criação do Fundo. Segundo os movimentos sociais ligados à Campanha, a proposta inicial do governo apresentava graves limitações à expansão e à melhoria da qualidade da Educação Básica no Brasil, pois, logo de início, excluía as creches.

A proposta do Governo inclui no FUNDEB apenas parte da Educação Infantil (atendimento em pré-escola para crianças de 4 a 6 anos de idade), deixando de fora os 13 milhões de crianças brasileiras na faixa etária de 0 a 3 anos. Isso é muito ruim porque: $88,3 \%$ das crianças brasileiras de 0 a 3 anos de idade não freqüentam creches pela falta de oferta; estudos científicos já comprovaram que o atendimento adequado nessa idade é fundamental para a formação da cidadania, da inteligência e das capacidades de aprendizagem que acompanharão a criança por toda a vida; fere o conceito de Educação Básica, excluindo aquela que seria parte de sua primeira etapa, com impacto altamente negativo na vida de milhões de crianças e de mulheres trabalhadoras, sobretudo de baixa renda (www.campanhaeducacao.org.br/fundebpravaler Acessado em 20 de janeiro de 2009).

Várias atividades foram realizadas pelas entidades filiadas à Campanha para exigir a inclusão das creches no Fundo. No Boletim da Campanha, chamado Fique por dentro ${ }^{9}$, 
de 15 de setembro de 2005, é apresentado um resumo das atividades realizadas para esse fim. Três manchetes chamam bastante à atenção: 1. FUNDEB pra Valer: "carrinhata" $e$ chocalhaço pressionaram parlamentares em Brasília; 2. Crianças cearenses fazem manifestação colorida e animada pelas creches no FUNDEB e; 3. Fraldas pintadas: protesto também na Câmara Municipal de Ribeirão Preto.

O Boletim Fique por dentro, de 05 de dezembro de 2005, traz o resultado da mobilização, com a seguinte manchete: "Creches são incluídas no FUNDEB".

O movimento "FUNDEB pra Valer!" conseguiu uma importante vitória na tramitação da PEC do FUNDEB. O atendimento em creches para crianças de 0 a 3 anos foi incluído no relatório da Comissão Especial que analisa a criação do novo fundo. A inclusão aconteceu depois de várias negociações entre os parlamentares da Comissão e os ministérios da Fazenda, do Planejamento e da Educação, além de muita pressão da sociedade civil.

Conquistado o objetivo principal do movimento, a Campanha seguiu a mobilização pelo que ela considerava aperfeiçoamento e pela aprovação do FUNDEB, durante quase todo o ano de 2006, enfrentando, inclusive, o intervalo do calendário eleitoral. E foi justamente com o processo eleitoral em curso que a mobilização quase viu todo o seu esforço se perder. O Congresso Nacional, na tentativa de acelerar a aprovação dos itens referentes ao salário-educação, de modo a liberar imediatamente os recursos desse mecanismo, resolveu promulgar instantaneamente o Fundo com as partes aprovadas pela Câmara e pelo Senado, sendo que o restante dos pontos que necessitavam de nova discussão deveria ser reenviado à Câmara como uma nova PEC.

Segundo Daniel Cara, coordenador da Campanha, rapidamente o movimento conseguiu mobilizar a bancada de apoio na Câmara para evitar que o Fundo fosse recortado, já que tal atitude "pode significar graves prejuízos aos avanços obtidos na atual proposta, o que poderia colocar em risco a aprovação dos pontos mais substantivos $e$ importantes do FUNDEB, como a antecipação da contribuição de $10 \%$ da União ao Fundo do quarto para o terceiro ano de sua vigência" (Carta Aberta aos Presidentes do Congresso e da Câmara Federal da Campanha Nacional pelos Direitos à educação, assinada por Daniel Cara, $2006^{10}$ ).

Passado o susto da pressa, a eleição toma conta de acalmar as iniciativas. Depois do segundo turno da eleição presidencial, os olhares do movimento voltam-se novamente para o Congresso e para a pauta de aprovação da PEC que acontece, finalmente, em 06 de dezembro de 2006.

No mesmo dia da aprovação dessa Proposta, a Campanha lança uma nota à sociedade brasileira, intitulada Aprovação do FUNDEB: um passo decisivo, considerando aquela data como o marco histórico de um importante passo do Brasil rumo à consagração do direito humano à educação básica para todos os brasileiros e brasileiras e exaltando a lei como o grande momento de participação democrática no Brasil.

Já no dia posterior à euforia, em 7 de dezembro de 2006, a Campanha vem com um POSICIONAMENTO PÚBLICO que, ao mesmo tempo em que repete os elogios da nota anterior, exige a continuação do processo de participação na regulamentação da Emenda recém-aprovada, como se pode ver abaixo:

REGULAMENTAÇÃO DO FUNDEB: o processo democrático como consagração dos direitos educacionais 
O movimento “FUNDEB pra Valer!”, liderado pela Campanha Nacional pelo Direito à Educação, entende como fundamental a tramitação e aprovação no Congresso Nacional da PEC 536/97, que cria o Fundo de Manutenção e Desenvolvimento da Educação Básica e Valorização dos Profissionais da Educação - FUNDEB.

Durante todo o rito legislativo, o movimento “FUNDEB pra Valer!" protagonizou inúmeras ações de pressão pública, proposição de emendas e estabelecimento de diálogo, que resultaram no aperfeiçoamento significativo e contínuo do texto da referida PEC. Na história da democracia brasileira, poucas leis foram elaboradas sob o prisma de um debate público tão expressivo, marcado por um intenso processo de negociação entre a Sociedade Civil e o Estado.

Os avanços obtidos por essa vigorosa experiência democrática são inúmeros. Em especial, a inclusão das creches na cobertura de financiamento do FUNDEB, a definição de um percentual mínimo para contribuição da União, a aceleração do tempo de investimento de recursos federais ao fundo - de cinco para quatro anos -, além da determinação de um piso salarial profissional nacional para o magistério, a ser regulamentado em lei específica.

Devido aos resultados positivos advindos do processo democrático de elaboração e discussão do texto da PEC do FUNDEB, o movimento "FUNDEB pra Valer!" considera imprescindível que a lei de regulamentação seja resultado de ampla discussão no Congresso Nacional, o que fortalece a perspectiva de continuação da incidência da sociedade civil no processo de criação do novo fundo, sobretudo no momento em que será definida a forma como esse será operacionalizado. Além disso, é preciso que o texto da lei de regulamentação:

1. Considere a essencialidade do investimento na ampliação das redes educacionais públicas, levando em conta as etapas e modalidades onde há demanda;

2. Estabeleça que as ponderações (fatores de diferenciação) quanto ao valor por alunolano por etapa e modalidade da educação básica - a que se refere o Art. 60, letra a), do inciso III, do ADCT - sejam estabelecidas levando em consideração a estimativa do custo real da respectiva etapa e modalidade;

3. Crie um mecanismo gradual de absorção dos atendimentos realizados por creches comunitárias conveniadas com a Prefeitura, considerando a necessidade de se financiarem esses estabelecimentos por um tempo determinado, permitindo a criação de políticas de transferências de matrículas para creches públicas;

4. determine mecanismos efetivos de controle social, especialmente no tocante aos conselhos de implementação do FUNDEB, tanto na esfera municipal, como na esfera federal.

Reforçamos que a experiência de elaboração do texto da PEC do FUNDEB é uma prova de que o processo democrático é a melhor forma para o aperfeiçoamento de uma lei. Acreditamos na essencialidade do estabelecimento de um canal efetivo de participação para a construção de uma regulamentação capaz de consagrar as conquistas obtidas a partir do texto da PEC.

\section{Comitê Diretivo da Campanha Nacional pelo Direito à Educação}

Em relação à perspectiva de uma ampla discussão no Congresso Nacional, a própria Campanha, posteriormente, admitiu que não haveria tempo de ser realizada da maneira como era idealizada por ela, pois os nós existentes tinham de ser desatados em pouco tempo, ao risco de que, se a regulamentação do FUNDEB não fosse aprovada até o fim do ano de 2006, o aporte de recursos previsto na PEC poderia se perder $^{11}$. O risco se transforma em pesadelo, ao se somar o fato de que o FUNDEF, que mantinha a 
sustentabilidade do Ensino Fundamental, deixaria de valer em 2006. Dessa forma, houve um acerto para que o governo regulamentasse o FUNDEB por Medida provisória.

No dia 28 de dezembro de 2006, segundo notícias do Portal do MEC, no salão de audiências do Palácio do Planalto, o presidente Lula, com a presença do presidente do Congresso, senador Renan Calheiros, do ministro da Educação, Fernando Haddad, do secretário de Educação Básica do MEC, Francisco das Chagas, da ministra Dilma Roussef, da Casa Civil, do ministro Tarso Genro, da Articulação Institucional, além de senadores, deputados, dirigentes do MEC, da Confederação Nacional dos Trabalhadores em Educação (CNTE), do Conselho Nacional dos Secretários de Educação (CONSED), da União Nacional dos Dirigentes Municipais de Educação (UNDIME), assessores e muitos jornalistas, assina a medida provisória que regulamenta o FUNDEB, em clima de euforia, compartilhada por todos os presentes (www.mec.gov.br/FUNDEB).

No entanto, no mesmo dia da referida solenidade, Jonas Valente, da Agência Carta Maior, escreve para o site do órgão: Regulamentação por medida provisória evita questões polêmicas. Assim, a regulamentação apressada por conta de prazos a cumprir adiou a tomada de algumas decisões.

\section{O Fundo e sua regulamentação}

O Fundo de Manutenção e Desenvolvimento da Educação Básica e de Valorização dos Profissionais da Educação (FUNDEB) substituiu o Fundo de Manutenção e Desenvolvimento do Ensino Fundamental e de Valorização do Magistério, que financiava apenas o Ensino Fundamental. Segundo o Ministério da Educação, o Fundo, que começa a se tornar realidade, tem por objetivo proporcionar a elevação e uma nova distribuição dos investimentos em educação. Contrariamente ao FUNDEF, que atendia somente aos alunos do Ensino Fundamental, o FUNDEB atenderia a todos os alunos da Educação Básica, incluindo creche escolar (zero a três anos), passando pela Educação Infantil, pelo Ensino Fundamental, chegando até o Ensino Médio. O FUNDEB abrange, ainda, a Educação de Jovens e Adultos e a Educação Indígena e Quilombola.

De acordo com a lei aprovada, o FUNDEB teria vigência de 14 anos, a contar do primeiro ano da sua implantação, ou seja, começou no ano de 2007 para ir até o ano de 2020. Sua implantação, porém, aconteceria de forma gradual e progressiva em três anos: 100\% dos alunos do Ensino Fundamental, mais um terço dos alunos das outras etapas (Educação Infantil, Ensino Médio, educação de jovens e adultos e educação indígena) no primeiro ano, dois terços, no segundo, e três terços (100\%), a partir do terceiro ano.

Um dos objetivos do FUNDEB é universalizar o atendimento na educação básica, a partir da redistribuição equitativa de recursos entre o estado e seus municípios. Foi estabelecido um valor mínimo por aluno, com valores diferenciados por etapa e modalidade de ensino da educação básica de todo o País.

Uma das principais mudanças do FUNDEB, em relação ao FUNDEF, é a fonte de recursos. Hoje o FUNDEF é composto por 15\% dos principais impostos e transferências dos estados e municípios: Fundo de Participação dos Estados (FPE), Fundo de Participação dos Municípios (FPM), Imposto de Circulação de Mercadorias e Serviços (ICMS), Imposto sobre Produtos Industrializados proporcional às Exportações (IPIexp) e a desoneração das exportações prevista na Lei Complementar nº 87/96 (Lei Kandir).

O FUNDEB prevê a manutenção das fontes que alimentam o FUNDEF, porém com alíquota maior (20\%), e ainda acrescenta novas fontes: o Imposto de Propriedade de Veículos Automotores (IPVA), Imposto de Transmissão de Causa Mortis e Doações (ITCMD), Cota Parte Municipal do Imposto Territorial Rural (ITR). Os impostos próprios dos municípios, no entanto, continuam fora do fundo (IPTU, ISS e ITBI). 
Quanto à subvinculação de recursos destinados à valorização do Magistério, permanece como no FUNDEF, em que, no mínimo, 60\% dos recursos constituintes do fundo deverão ser aplicados na remuneração do Magistério.

No primeiro ano de vigência do FUNDEB, o aporte da União, já reservado no orçamento de 2007, foi de $\mathrm{R} \$ 2$ bilhões; os recursos de impostos municipais e estaduais aumentaram de $15 \%$ para $16,66 \%$ - os impostos que fazem parte do FUNDEF, mais 6,66\% dos novos impostos; seriam atendidos $100 \%$ dos alunos do Ensino Fundamental e um terço dos alunos excluídos do FUNDEF (Educação Infantil, Ensino Médio e Educação de Jovens e Adultos). Estimava-se que o FUNDEB movimentaria, no primeiro ano, R $\$ 43,1$ bilhões (41, 1 bilhões de Estados e municípios e 2 bilhões da União).

No segundo ano, o aporte da União previsto foi de R\$ 3 bilhões; os recursos de impostos municipais e estaduais aumentaram para 18,33\% e 13,33\% (novos impostos); seriam atendidos $100 \%$ dos alunos do Ensino Fundamental e dois terços dos das outras etapas de ensino. Supunha-se que o FUNDEB movimentaria R \$ 48,9 bilhões no segundo ano ( $\mathrm{R} \$ 45,9$ bilhões de estados e municípios mais os três bilhões de reais da União).

No terceiro ano, o aporte da União deveria ser de $\mathrm{R} \$ 4,5$ bilhões; os recursos de impostos municipais e estaduais aumentariam para 20\% (todos os impostos); seriam atendidos $100 \%$ dos alunos do Ensino Fundamental e $100 \%$ dos das outras etapas. Calculava-se que o FUNDEB movimentaria $\mathrm{R} \$ 55,2$ bilhões no terceiro ano, somados à parte dos estados e dos municípios mais a parte da União.

A partir do quarto ano, previa-se que o aporte da União seria de $10 \%$ da contribuição dos estados e municípios (cerca de $\mathrm{R} \$ 5,1$ bilhões); os recursos de impostos municipais e estaduais seriam fixados em 20\%; $100 \%$ dos alunos da educação básica seriam atendidos. A parcela de estados e municípios corresponderia a $\mathrm{R} \$ 50,7$ bilhões, com a previsão de que o FUNDEB movimentaria $\mathrm{R} \$ 55,8$ bilhões, a partir do quarto ano de implementação.

Dessa maneira, após o quarto ano de vigência, as previsões deram conta de que seriam beneficiados cerca de 48,1 milhões de estudantes da educação básica, sendo cerca de 860 mil de creches; 4,1 milhões, de pré-escolas; cerca de 34,1 milhões, do Ensino Fundamental, e cerca de 9 milhões, do Ensino Médio.

Recursos previstos para o FUNDEB, oriundos dos Estados, dos Municípios e da União, e o percentual de alunos beneficiados por modalidade de ensino/ano

\begin{tabular}{|c|c|c|c|c|c|}
\hline \multirow{2}{*}{$\begin{array}{c}\text { Escala de } \\
\text { implantação do } \\
\text { FUNDEB }\end{array}$} & \multicolumn{3}{|c|}{$\begin{array}{l}\text { Recursos previstos } \\
\text { (R\$ bilhões, em } \\
\text { valores de 2006) }\end{array}$} & \multicolumn{2}{|c|}{$\begin{array}{l}\text { Percentual de alunos considerados } \\
\text { na distribuição de recursos }\end{array}$} \\
\hline & $\begin{array}{l}\text { dos estados e } \\
\text { municípios }\end{array}$ & da União & total & $\begin{array}{c}\text { Ensino Fundamental } \\
\text { e Especial }\end{array}$ & $\begin{array}{c}\text { Pré-escola, } \\
\text { Ensino Médio } \\
\text { e EJA }\end{array}$ \\
\hline $1^{\circ}$. Ano & 41,1 & 2,0 & 43,1 & $100 \%$ & $1 / 3(33,3 \%)$ \\
\hline $2^{\circ}$. Ano & 45,9 & 3,0 & 48,9 & $100 \%$ & $2 / 3(66,6 \%)$ \\
\hline $3^{\circ}$. Ano & 50,7 & 4,5 & 55,2 & $100 \%$ & $3 / 3(100 \%)$ \\
\hline $\begin{array}{c}\text { do } 4^{\circ} \text {. ao } 14^{\circ} \text {. } \\
\text { Ano }\end{array}$ & 50,7 & 5,1 & 55,8 & $100 \%$ & $100 \%$ \\
\hline
\end{tabular}

Fonte: MEC 
A regulamentação do Fundo, como já foi dito anteriormente, deu-se por Medida Provisória (339/2006 de 28/12/2006), detalhando-se as regras para a transferência, a gestão e o controle dos recursos, mas se protelando algumas questões polêmicas.

Pontos principais definidos pela MP:

1. Foi mantido como principal critério de distribuição dos recursos o número de matrículas registrado no censo escolar;

2. Foi instituído parâmetro de coeficientes entre 0,7 (zero vírgula sete) e 1,3 (um vírgula três), dentro do qual, terá que ser feita a divisão dos recursos do Fundo. Tendo como base o Ensino Fundamental de $1^{\mathrm{a}}$ a $4^{\mathrm{a}}$ série, que representará 1 (UM), a regra significa que nenhum dos demais níveis de ensino receberá no máximo $30 \%$ a mais do que o Ensino Fundamental e, no mínimo, 30\% a menos;

3. Foi determinado o controle social sobre os recursos. A MP prevê a criação de conselhos nos três âmbitos da Federação, compostos por governos, trabalhadores, pais e estudantes, com a responsabilidade de fiscalizar a aplicação dos recursos do FUNDEB e o censo escolar estadual ou local. Os conselhos também devem participar da elaboração das propostas orçamentárias anuais de cada ente federado. Um dos papéis dessas instâncias será evitar desvios na informação sobre as matrículas de cada estado ou município;

4. Foi instituída, no âmbito do Ministério da Educação, a Junta de Acompanhamento dos Fundos, com o fim de especificar anualmente as ponderações aplicáveis à distribuição proporcional dos recursos, com a seguinte composição: I - um representante do Ministério da Educação, que a presidirá; II - um representante do Conselho Nacional de Secretários de Estado da Educação - CONSED; e III - um representante da União Nacional dos Dirigentes Municipais de Educação - UNDIME.

Os pontos polêmicos que a Medida Provisória deixou de fora são:

1. A determinação dos coeficientes para divisão dos recursos. Quanto equivalerá cada aluno, em cada um dos níveis de ensino atendidos, será determinado pela Junta de Acompanhamento do FUNDEB. A previsão de prazo para que isso seja definido é até o final do mês de Janeiro de 2007. Assim, a disputa será feita dentro dessa junta, formada por representantes dos secretários estaduais e municipais de educação, tendo o MEC como mediador. A briga deverá ser entre estados e municípios para aumentar o coeficiente de recursos referentes à parte de alunos que eles atendem.

2. A decisão de que, se o pagamento dos aposentados da educação nos Estados e municípios poderá ser feita com os recursos do FUNDEB. Da mesma forma que o FUNDEF não determinou nenhuma regra sobre isso, deixando essa função para a interpretação dos Tribunais de Contas dos Estados, a regulamentação do FUNDEB, atendendo à reivindicação dos Estados, não ousou mexer com esse problema. Segundo o Ministro Haddad, o MEC pretende propor ao Congresso a proibição, mas com um prazo de cinco a 10 anos para que Estados e municípios se adaptem (Jornal Estado de São Paulo, 28/12/2007);

3. A determinação do piso salarial nacional para os professores que atuam na educação básica. A proposta do MEC é o encaminhamento de um projeto de lei ao Congresso Nacional para deliberar sobre esse assunto.

O primeiro dos pontos polêmicos, foi logo resolvido. Em fevereiro de 2007, a Junta de Acompanhamento, formada por representantes do Ministério da Educação, do Conselho Nacional de Secretários de Educação e da União Nacional dos Dirigentes Municipais de Educação, definiu os coeficientes para a distribuição dos recursos. Os fatores de ponderação foram especificados através da Portaria do MEC número 01/2007. A tabela abaixo apresenta o fator de cada modalidade de ensino com seu respectivo valor em real. 
Fatores de ponderação e valor mínimo nacional por aluno - 2007

\begin{tabular}{|l|c|c|}
\hline & Fator & Valor (R $\$)$ \\
\hline 1. Creche & 0,80 & 757,03 \\
\hline 2. Pré-escola & 0,90 & 851,66 \\
\hline 3. Séries iniciais do ensino fundamental urbano & 1,00 & 946,29 \\
\hline 4. Séries iniciais do ensino fundamental rural & 1,05 & 993,61 \\
\hline 5. Séries finais do ensino fundamental urbano & 1,10 & 1040,92 \\
\hline 6. Séries finais do ensino fundamental rural & 1,15 & 1088,24 \\
\hline 7. Ensino fundamental em tempo integral & 1,25 & 1182,86 \\
\hline 8. Ensino médio urbano & 1,20 & $1.135,55$ \\
\hline 9. Ensino médio rural & 1,25 & $1.182,86$ \\
\hline 10. Ensino médio em tempo integral & 1,30 & $1.230,18$ \\
\hline 11. Ensino médio integrado à educação profissional & 1,30 & $1.230,18$ \\
\hline 12. Educação especial & 1,20 & $1.135,55$ \\
\hline 13. Educação indígena e quilombola & 1,20 & $1.135,55$ \\
\hline 14. Educação de jovens e adultos com avaliação no processo & 0,70 & 662,40 \\
\hline $\begin{array}{l}\text { 15. Educção de jovens e adultos integrada à educação profissional de nível } \\
\text { médio, com avaliação no processo }\end{array}$ & 0,70 & 662,40 \\
\hline
\end{tabular}

Fonte: MEC

Vale salientar que os fatores de ponderação sofreram mudanças, em algumas modalidades de ensino, nos anos de 2008, 2009 e 2010. Abaixo, podem-se acompanhar os valores anunciados nos três anos referidos, através das Portarias no 41/2007, $n^{\circ}$. 932/2008 e $n^{\circ} 777 / 2009$ do Ministério da Educação, respectivamente.

Fatores de ponderação 2008, 2009 e 2010

\begin{tabular}{|l|l|l|l|}
\hline & 2008 & 2009 & 2010 \\
\hline 1. Creche pública em tempo integral & 1,10 & 1,10 & 1,10 \\
\hline 2. Creche pública em tempo parcial & 0,80 & 0,80 & 0,80 \\
\hline 3. Creche conveniada em tempo integral & 0,95 & 0,95 & 1,10 \\
\hline 4. Creche conveniada em tempo parcial & 0,80 & 0,80 & 0,80 \\
\hline 5. Pré-Escola em tempo integral & 1,15 & 1,20 & 1,25 \\
\hline 6. Pré-Escola em tempo parcial & 0,90 & 1,00 & 1,00 \\
\hline 7. Anos iniciais do Ensino Fundamental urbano & $\mathbf{1 , 0 0}$ & $\mathbf{1 , 0 0}$ & $\mathbf{1 , 0 0}$ \\
\hline 8. Anos iniciais do Ensino Fundamental no campo & 1,05 & 1,05 & 1,15 \\
\hline 9. Anos finais do Ensino Fundamental urbano & 1,10 & 1,10 & 1,10 \\
\hline 10. Anos finais do Ensino Fundamental no campo & 1,15 & 115 & 1,20 \\
\hline 11.Ensino Fundamental em tempo integral & 1,25 & 1,25 & 1,25 \\
\hline 12. Ensino Médio urbano & 1,20 & 1,20 & 1,20 \\
\hline 13. Ensino Médio no campo & 1,25 & 1,25 & 1,25 \\
\hline 14. Ensino Médio em tempo integral & 1,30 & 1,30 & 1,30 \\
\hline 15. Ensino Médio integrado à educação profissional & 1,30 & 1,30 & 1,30 \\
\hline 16. Educação Especial & 1,20 & 1,20 & 1,20 \\
\hline 17. Educção indígena e quilombola & 1,20 & 1,20 & 1,20 \\
\hline 18. Educação de Jovens e Adultos com avaliação no processo & 0,70 & 0,80 & 0,80 \\
\hline $\begin{array}{l}\text { 19. Educação de Jovens e Adultos integrada à educação profissional de nível } \\
\text { médio, com avaliação no processo }\end{array}$ & 0,70 & 1,00 & 1,00 \\
\hline
\end{tabular}

Fonte: MEC

Os coeficientes apresentados, com o ensino médio "valendo" mais do que o ensino fundamental, possibilita observar que os estados conseguiram levar vantagem na disputa pelos recursos com os municípios. A pressão dos governadores, alegando perdas passadas com o FUNDEF, já que o dinheiro era repassado conforme o número de matrículas no 
ensino fundamental da rede pública, surtiu efeito. O segundo ponto pendente teve que esperar pela aprovação da Lei do FUNDEB na Câmara dos Deputados. Já no prazo final para "caducar" a Medida Provisória 339 de 2006, a lei é aprovada. O Presidente Lula sancionou a lei 11.494 no dia 20 de junho. A solenidade aconteceu no Palácio do Planalto e contou com a presença do ministro da Educação, Fernando Haddad e de representantes de diversos segmentos sociais que acompanharam o processo de discussão e aprovação do Fundo.

Entre suas determinações, estabelece, no artigo 22, que "pelo menos $60 \%$ (sessenta por cento) dos recursos anuais totais dos Fundos serão destinados ao pagamento da remuneração dos profissionais do magistério da educação básica em efetivo exercício na rede pública" (grifos meus). Para não haver dúvidas, o parágrafo único esclarece:

Parágrafo único. Para os fins do disposto no caput deste artigo, considerase:

I - remuneração: o total de pagamentos devidos aos profissionais do magistério da educação, em decorrência do efetivo exercício em cargo, emprego ou função, integrantes da estrutura, quadro ou tabela de servidores do Estado, Distrito Federal ou Município, conforme o caso, inclusive os encargos sociais incidentes;

II - profissionais do magistério da educação: docentes, profissionais que oferecem suporte pedagógico direto ao exercício da docência: direção ou administração escolar, planejamento, inspeção, supervisão, orientação educacional e coordenação pedagógica;

III - efetivo exercício: atuação efetiva no desempenho das atividades de magistério previstas no inciso II deste parágrafo associada à sua regular vinculação contratual, temporária ou estatutária, com o ente governamental que o remunera, não sendo descaracterizado por eventuais afastamentos temporários previstos em lei, com ônus para o empregador, que não impliquem rompimento da relação jurídica existente.

E, finalmente, o ponto mais esperado pelos professores. O piso salarial para o magistério. A Lei $\mathrm{n}^{\circ} 11.738 / 2008$, que dispõe sobre o piso salarial profissional nacional para os profissionais do magistério público, foi sancionada pelo presidente no dia 16 de julho de 2008, um ano e meio depois da Medida provisória do FUNDEB. Segundo a APEOESP, além de um valor muito abaixo do esperado pela categoria, os novecentos e cinqüenta reais iniciais para uma jornada de trabalho de 40 (quarenta) horas, ainda deve esperar até 2010 para atingir todo o território nacional.

\section{Perspectivas de atendimento das demandas da educação básica e, em particular, do Ensino Médio com o FUNDEB.}

Depois de apresentar a mobilização da sociedade civil, em prol da aprovação do Fundo da Educação Básica e de alguns elementos constituintes dele, cabe agora uma reflexão sobre a contribuição de que o FUNDEB, bem como todo o processo que levou a ele, pode beneficiar a qualidade na educação. A primeira questão é exatamente a validade ou não de um fundo específico para a educação.

Logo após a aprovação da PEC do FUNDEB, no Senado, Nicholas Davies, professor da Faculdade de Educação da Universidade Federal Fluminense, escreveu um 
artigo para a Revista Educação e Sociedade, com o objetivo de examinar "alguns aspectos básicos do financiamento da educação estatal no Brasil, focalizando especialmente a política de fundos" apresentada pelos governos federais nos últimos dez anos (DAVIES, 2006, p. 754).

Para o autor, o debate sobre a validade de fundos precisa atentar para o fato de a vinculação de impostos configurar, em si mesma, um fundo. É um fundo, embora sem esse nome, porque reserva constitucionalmente parte dos impostos para a educação. "Ora, é pouco provável que haja discordância no campo educacional sobre a importância e a validade da vinculação" (p. 755), defende ele. O que acontece é que a referência de fundos que se tem é o FUNDEF que, ao estipular uma cesta de impostos exclusivos para uma modalidade de ensino, deixou sem financiamento, ou com financiamento precário, outras modalidades.

Dessa forma, mesmo sem se colocar totalmente contra a ideia do fundo formal ${ }^{12}$ para algum setor da educação, o autor pondera que um grande risco é de eles agravarem a fragmentação da educação escolar, ao privilegiar um nível de ensino em detrimento de outros níveis. Para Davies, "a educação não pode ser pensada em pedaços, como se uma parte (a graduação ou a pós-graduação, por exemplo) pudesse funcionar bem sem as outras (a educação básica, por exemplo). Só uma perspectiva de totalidade, abrangendo desde a creche até a pós-graduação, pode enfrentar alguns dos problemas básicos da educação" (2006, p. 755).

Concordando com o autor, ressalto que a corrida pelo Ensino Médio se deu depois de um investimento do FUNDEF no Ensino Fundamental. Tal corrida encontrou essa modalidade de ensino totalmente despreparada para receber a demanda. A forma encontrada para agregar novos alunos à estrutura do Ensino Médio foi precarizando e improvisando, como acentuado antes. Com a mesma ideia de Fundo formal, no que pesa que este engloba desde a creche escolar até o Ensino Médio, a previsão é de que aumente a dificuldade de recursos no já cambaleante Ensino Superior. Pode-se prever que o Ensino Superior público deverá sofrer, medidas as proporções, o que o Ensino Médio passou e ainda passa.

Outro sério problema dos fundos é que eles não se baseiam nas necessidades de uma educação de qualidade, mas sim, num "percentual fixo e inflexível dos impostos, que é tido pelas autoridades como limite máximo, e não mínimo, como prevê a vinculação para a educação" (idem, ibidem). Assim, a referência de investimento passa a ser o percentual determinado sem considerar se isso é suficiente para atender às necessidades educacionais da população. E mais: "no âmbito federal, a proporção deles na receita global vem caindo em favor das contribuições (o CPMF é o exemplo mais recente), as quais não entram na base de cálculo dos recursos federais vinculados à MDE [Manutenção e Desenvolvimento do Ensino] e tampouco são transferidas aos estados, ao Distrito Federal e aos municípios" (idem, ibidem). Somado a tudo isso, ainda tem o descumprimento da lei dos fundos por parte do governo federal e dos governos estaduais e municipais, como por exemplo, o que o MEC fez, desde 1998, ao estipular um custo/aluno abaixo do que determina a lei, ou como fez o governo de São Paulo (em 2001), ao incluir os profissionais inativos na conta dos $60 \%$ destinados aos profissionais da educação, em efetivo exercício do Magistério, ou, ainda, as diversas irregularidades apuradas pela CPI do FUNDEF, na Assembleia Legislativa do Ceará, indo desde desvios de recursos, notas fiscais frias e cursos de capacitação e formação de professores que nunca existiram. É bom lembrar que, em todos os casos citados, nenhuma responsabilidade foi punida, seja por causa de brechas encontradas na lei ou da lentidão judicial. 
Outro grande problema é que a repartição dos recursos do fundo, como está previsto no FUNDEB, e como era também no FUNDEF, pode acirrar o corporativismo dos que trabalham na educação ao determinar a remuneração para os profissionais do Magistério da educação básica, deixando de fora os demais trabalhadores da educação. Assim como um hospital não é feito só por médicas (o) e enfermeiras (o), uma escola não se limita às professoras e aos professores. Funcionários, em suas diversas funções (limpeza, cantina, laboratórios, biblioteca, secretaria, almoxarifado, vigilância e portaria), devem ser valorizados com salários condizentes e capacitações que, para além dos discursos vazios, reforcem a ideia de que, principalmente em um ambiente escolar, todos são educadores. A valorização da educação deve se dar com a valorização de todos os seus profissionais, e não, estabelecendo subdivisões que podem, na melhor das hipóteses, gerar hierarquização de funções, deseducando, na prática cotidiana, a lição de que não devemos separar a sociedade em uma classe que pensa e a outra que executa.

A segunda questão diz respeito à mobilização.

É fato que a mobilização de uma parte interessada e bem informada da sociedade civil ligada à educação foi crucial para que o FUNDEB ultrapassasse a primeira emenda apresentada pelo MEC, melhorando-a substancialmente. Essa mobilização conseguiu incluir as creches, aumentar um pouco as previsões de repasses do governo federal, diminuir o tempo de transição da implementação, de quatro, para três anos, e aumentar de dez, para catorze anos, a sua existência.

Entretanto, por que essa ampla mobilização não se deu anteriormente para forçar o governo federal - no período FHC ou no período Lula - a cumprir a lei que estabelece um custo aluno/maior? Por que também não teve força suficiente para pressionar o governo Lula, logo no início de seu mandato, a enviar a proposta do FUNDEB ao Congresso Nacional?

Ora, o FUNDEB é uma reivindicação histórica dos profissionais da educação. O próprio Partido dos Trabalhadores (PT), que tem sua história ligada aos movimentos reivindicatórios, apresentou uma proposta de emenda constitucional em 1999 para instituir o FUNDEB ${ }^{13}$. Nada mais apropriado do que aproveitar o cacife eleitoral do governo eleito para efetuar as mudanças prioritárias na educação logo no início de 2003. Infelizmente, as reformas feitas foram a previdenciária e a trabalhista, que tiram direitos sociais conquistados em momento de ascenso de setores progressistas e organizados da sociedade. Diante disso, o que se viu não foi nenhuma mobilização, mas a letargia de vários setores, antes, organizados, e agora, paralisados diante da figura do governo de esquerda. $\mathrm{O}$ Executivo levou a proposta ao Congresso no momento em que bem quis. E o momento, segundo Davies (2006), foi aquele em que o governo se viu acuado com as denúncias do mensalão e já ecoava, no Congresso e na mídia (apesar de nenhum respaldo na maioria da população), a incômoda palavra do impeachment do presidente. A proposta da PEC do FUNDEB, em 2005, não parece ter sido porque o governo estava seriamente preocupado em revolucionar a educação, mas porque necessitava "melhorar sua imagem desgastada $e$ recuperar a iniciativa política" (p. 760). Dessa forma, a agenda política, não só do Legislativo mas também dos movimentos sociais, com raríssimas e gratas exceções (como o MST), ficou quase que totalmente nas mãos do Executivo.

O descumprimento da lei do FUNDEF, relativo ao custo/aluno, reforça a ideia anterior. Essa irregularidade, segundo dados do próprio MEC (DAVIES, 2006), significou que o governo federal deixou de contribuir com mais de $\mathrm{R} \$ 12,7$ bilhões entre os anos 1998 e 2002. Para o período do governo Lula, a previsão era de que a dívida com a educação somasse $\mathrm{R} \$ 30$ bilhões até o final de 2006. A “complementação deveria ter sido em torno de $R \$ 5$ bilhões só em 2004, não de $R \$ 485$ milhões, se o governo tivesse 
calculado o valor mínimo conforme manda a Lei n. 9.424" (p. 757). A mobilização que se mostrou eficaz e encontrou terreno fértil para ganhar força e impor algumas conquistas não conseguiu perseguir nem o governo Lula que, em tese, é mais próximo dos movimentos reivindicatórios, que a lei fosse cumprida.

Devido a isso, não deixa de ser temeroso que alguns aspectos dessa lei possam ficar somente no papel, como a contribuição maior da União para o fundo, e o movimento social, que contribuiu para a sua aprovação, continue a fiar o governo com a espera paciente devido à história do PT e de seu líder presidente.

É preciso convir que, caso "o governo pretendesse fazer uma complementação federal significativa para a educação básica dos estados, Distrito Federal e municípios, poderia tê-la feito para o FUNDEF desde 2003, porém não o fez, sendo tal complementação, além de muito aquém da prevista na lei do FUNDEF (n. 9.424), decrescente em termos reais e percentuais e correspondentes, em 2006, a cerca de $1 \%(R \$$ 313 milhões) da previsão da receita nacional do FUNDEF (R\$ 35 bilhões)" (idem, ibidem). Convém lembrar que o próprio PT, em 1999, denunciava e apelava com uma Representação do Ministério Público Federal, exigindo que o Presidente da República, na época, Fernando Henrique, fosse responsabilizado juridicamente por descumprimento sistemático da Lei do FUNDEF. Segundo a bancada petista da época, "o não cumprimento da Lei do FUNDEF ating[ia] 20 milhões de crianças que freqüenta[vam] escolas localizadas nos quinze estados mais pobres da Federação" (SANTOS, 2004, p.17). O tempo passa, e o governo do PT, mais aliados, mantém a mesma posição que outrora condenava. Mais uma vez, o grande movimento da sociedade civil, que foi competente para impor mudanças significativas na PEC do FUNDEB, não conseguiu fazer nenhum eco pressionar o governo e seu partido a cumprirem com as próprias propostas. A mobilização se perdeu em algum momento entre a burocratização e o atrelamento dos sindicatos, das entidades representativas (como a CUT e a CNTE) e do Partido dos Trabalhadores, incapazes de resolver o dilema shakesperiano de ser ou não ser governo.

A terceira questão diz respeito aos recursos novos para compor o FUNDEB que, como foi aprovado e até agora regulamentado, traz poucos recursos novos para o sistema educacional como um todo, uma vez que apenas redistribui $20 \%$ de grande parte dos recursos, que já são constitucionalmente vinculados à educação, entre o governo estadual e as prefeituras, com base no número de matrículas na educação básica. Isso significa que uns governos ganharão, mas outros perderão na mesma proporção, sobretudo quando não houver complementação federal, que será o único recurso novo para o sistema educacional.

A complementação federal prevista para o ano de 2007 era de dois bilhões de reais e deveria chegar até $10 \%$ (dez por cento) do total aplicado por estados e municípios a partir de 2010, o que poderia equivaler a 5,1 bilhões de reais. Apesar da cifra grandiosa, esses valores eram muito poucos, porque correspondiam ao que o governo federal tirava da educação com a Desvinculação das Receitas da União (DRU), que desvinculava $20 \%$ dos impostos destinados à educação. A DRU ${ }^{14}$ estaria em vigor até 2007 e, como previa o autor, poderia ser prorrogada indefinidamente, como vários governos fizeram desde 1994, quando essa desvinculação foi criada com o nome de Fundo Social de Emergência e transformada depois em Fundo de Estabilização Fiscal (DAVIES, 2006).

Quando se considera que a média anual de complementação para o FUNDEF, de 1998 até 2005, não passou de $\mathrm{R} \$ 500$ milhões, os novos valores do governo federal ainda são aparentemente generosos. Entretanto, como mostra Davies, se o governo tivesse cumprido a lei do FUNDEF, a complementação teria sido de vários bilhões anuais, como denunciado pelo Tribunal de Contas da União por parlamentares e entidades sindicais e governamentais, outrora críticas do governo FHC. Dessa maneira, mesmo os R $\$ 4,5$ 
bilhões previstos de complementação para o terceiro ano do FUNDEB estão aquém do devido legalmente, se o fundo fosse apenas do Ensino Fundamental. "Ora, como o FUNDEB abrange toda a educação básica, não apenas o ensino fundamental, os $R \$ 4,5$ bilhões não são tão significativos assim" (p. 765). Em termos absolutos, principalmente, nos três primeiros anos de implementação do fundo da educação básica, o governo federal está contribuindo menos do que deveria ter contribuído somente para o fundo do Ensino Fundamental. Como alerta Davies, "os valores previstos para os primeiros quatro anos não são significativos em termos nacionais e da capacidade financeira da União. No primeiro ano, por exemplo, a complementação de $R \$ 2$ bilhões representará bem menos de $5 \%$ da receita total do FUNDEB, sendo os $95 \%$ restantes contribuições dos estados $e$ municípios. Mesmo no quarto ano, a previsão de no mínimo $10 \%$ do FUNDEB continuará sendo muito pouco, tendo em vista a maior participação do governo federal na receita tributária nacional” (2006, p. 765).

A gradualidade de implementação do fundo - tanto na contabilidade dos alunos que vão fazer parte dele (1/3 por ano), quanto da participação financeira da União (que começa com 2\%) - contribui para aumentar o déficit, principalmente, do Ensino Médio. Numa situação em que a União já tem uma dívida astronômica com o FUNDEF, admitida até pelo próprio governo, a protelação dos recursos para o novo fundo não é coerente. Imaginemos uma situação de extrema penúria por que passa uma modalidade de ensino e, depois de quatro anos do governo que defende a bandeira da educação (em tese), aprova-se uma lei em que se exigem mais quatro anos para começar a pagar uma pequena parte do que lhe é devido. Fazer festa para uma proposta assim, mesmo considerando seus avanços, parece muito precipitado. Talvez, manter a guarda levantada e preparar os embates que virão para que essa lei não se transforme em mais uma que não sai do papel seja a postura mais adequada.

Por fim, a falta de mais dinheiro novo para a educação pode comprometer a chamada valorização dos profissionais do Magistério. Na avaliação de Davies (2006, p. 766), é um equívoco

supor que a destinação de $60 \%$ para remunerar profissionais do magistério resultará necessariamente em sua "valorização", entendendo por isso a melhoria salarial. É um equívoco por várias razões. Uma é que o FUNDEB não representará a totalidade dos recursos vinculados à educação, pois deixará de fora as seguintes receitas: (a) o salárioeducação, (b) $25 \%$ (ou um percentual maior, se previsto como mínimo na Lei Orgânica) dos impostos municipais próprios (IPTU, ISS, ITBI) e do imposto de renda (IR) dos servidores municipais, bem como $25 \%$ (ou um percentual maior, se previsto como mínimo na Constituição Estadual) do IR dos servidores estaduais, (c) 5\% dos impostos do FUNDEB que não entram na sua formação (ou a diferença entre os $20 \%$ dos impostos do FUNDEB e o percentual mínimo fixado pela Lei Orgânica ou a Constituição Estadual, como é o caso de São Paulo, Rio Grande do Sul e outros). Assim, o percentual mínimo de $60 \%$ não será significativo, porque não é baseado na totalidade dos recursos da educação (grifos nossos).

Portanto, não há nenhuma garantia de que isso ocorra. A experiência do FUNDEF demonstrou que os $60 \%$ (sessenta por cento) da receita do Fundo não resultaram em melhoria salarial, a ponto de se considerarem os trabalhadores em educação valorizados. Pelo contrário, qualquer reivindicação salarial caía na armadilha dos $60 \%$ (sessenta por cento) do FUNDEF, considerados pelos gestores, principalmente prefeitos e secretários 
municipais, como o limite máximo possível de gasto, o que nunca foi verdade. Na disputa entre os interesses dos trabalhadores em educação e os governos municipais, prevaleceram os $60 \%$ (sessenta por cento) como o máximo possível para o pagamento dos professores, e não, como o mínimo necessário.

\section{Referências}

APEOESP - Sindicato dos Professores do Ensino Oficial do Estado de São Paulo. Suplemento especial. São Paulo, APEOESP, 1997.

APEOESP. "FUNDEB: Luta é no Senado". O Jornal da Apeoesp (número 269). Junho de 2006.

APEOESP. "Vitória dos trabalhadores em educação: Senado aprova FUNDEB". Informativo eletrônico da APEOESP, Fax nº 38. 06/07/2006. Brasília: MEC, 1999.

BRASIL. Ministério da Educação. Grupo de Trabalho de Reestruturação e Expansão do Ensino Médio no Brasil. Relatório Final. Brasília, MEC, 2008.

CAMPANHA Nacional Pelo Direito à Educação. Boletim Fique Por Dentro. "Creches são incluídas no FUNDEB”. 05/12/2005. Disponível em www.campanhaeducacao.org.br

CAMPANHA Nacional pelo Direito à Educação. Nota à Sociedade Brasileira. Aprovação do FUNDEB: um passo decisivo. 6 de dezembro de 2008. Disponível em www.campanhaeducacao.org.br

CAMPANHA Nacional pelo Direito à Educação. Carta Aberta aos Presidentes do Congresso e da Câmara Federal. 09 de novembro de 2008. Disponível em www.campanhaeducacao.org.br.

CONGRESSO em foco. Regulamentação do FUNDEB gera polêmica. 20 de dezembro de 2006. Disponível em www.congressoemfoco.com.br acessado em 21 de janeiro de 2009.

COSTA, Vera Lúcia Cabral. Financiamento e gasto com o Ensino Médio no Brasil in: Revista Em Aberto, v. 18, n. 74, Brasília, INEP/MEC, 2001 b.

DAVIES, Nicholas. FUNDEB: a redenção da educação básica? Revista Educação e Sociedade, Campinas, v. 27, n. 96, 2006.

FERREIRA, Marieta de Moraes \& AMADO, Janaína. Usos e abusos da história oral. Rio de Janeiro, FGV, 1996.

FERRETI, Celso João et al. Novas tecnologias, trabalho e educação: um debate multidisciplinar. Petrópolis, RJ, Vozes, 1994.

HADDAD, Sérgio, Relatoria Nacional para o Direito Humano à Educação: o direito à educação no Brasil, Rio de Janeiro, DHESC, 2003.

HIRATA, Helena. Da polarização das qualificações ao modelo da competência, in:

KRAWCZYK, Nora; ZIBAS, Dagmar. Reforma do Ensino Médio no Brasil. Educação Brasileira, SP, 2001

KUENZER, Acácia Zeneida. O Ensino Médio agora é para a vida: entre o pretendido, o dito e o feito. Educação \& Sociedade, Campinas, v. 21, n. 70, p. 15-40, abr. 2000.

LACOUTURE, Jean. A história imediata. In LE GOFF, Jacques. A história nova. São Paulo, Martins Fontes, 1993. 
SANTOS, Jean Mac Cole Tavares. Para além do Ensino Médio: a região, o mundo do trabalho e a nova sociabilidade. In BRENNAND, Edna. GALVÃO, Neuma (orgs). Múltiplos saberes e educação. João Pessoa, Editora Universitária UFPB, 2004.

SANTOS, Jean Mac Cole Tavares. Do novo Ensino Médio aos problemas de sempre: entre marasmos, apropriações e resistências escolares. Fortaleza: UFC edições, 2008.

Notas:

\footnotetext{
${ }^{1}$ Professor adjunto da Faculdade de Educação da UERN. Parte de projeto de pesquisa sobre o mundo do trabalho e formação secundária, financiado pelo CNPq e pela FUNCAP. E-mail: maccolle@ hotmail.com

${ }^{2}$ Informações retiradas do portal da Secretaria de Educação Básica do MEC: http://portal.mec.gov.br/seb. Acessado em 20 de janeiro de 2007.
}

${ }^{3}$ A Campanha representa a ação de mais de 120 instituições de todo o Brasil, incluindo ONGs nacionais e internacionais, sindicatos, universidades, secretárias e secretários de educação e organizações estudantis e juvenis. O Comitê Diretivo da Campanha é responsável pela definição das estratégias políticas da Campanha, comprometidas com a implementação das grandes metas pactuadas em Assembleia Geral. Oito instituições formam o Comitê, que se reúne, presencialmente, duas vezes por ano, e a distância, por meio de teleconferências periódicas. Mas é a Internet que confere coesão e agilidade à Campanha. A troca de mensagens, arquivos e informações possibilita a comunicação permanente. Atualmente, fazem parte do Comitê Diretivo: Ação Educativa; ActionAid do Brasil; Centro de Defesa da Criança e do Adolescente do Ceará - Cedeca; Centro de Cultura Luiz Freire - CCLF; Confederação Nacional dos Trabalhadores em Educação - CNTE; Movimento dos Trabalhadores Rurais Sem Terra - MST; União Nacional dos Dirigentes Municipais de Educação - UNDIME; União Nacional dos Conselhos Municipais de Educação - UNCME.

${ }^{4}$ Trata-se da Proposta de Emenda à Constituição (PEC 112/99), apresentada pelos parlamentares do Núcleo de Educação, Cultura e Desporto do Partido dos Trabalhadores no Congresso Nacional. A proposta do FUNDEB ganhou destaque no Programa de Governo do então candidato, Luiz Inácio Lula da Silva, em 2002.

5 www.cnte.org.br/FUNDEF

${ }^{6}$ www.cnte.org.br/informa/cnteinforma

${ }^{7}$ Juçara Dutra Vieira, filiada ao PT, foi candidata à primeira suplência na chapa de Miguel Rosseto ao Senado. Com o seu licenciamento da presidência da CNTE, assumiu interinamente a professora Raquel Felau Guisoni.

${ }^{8}$ www.campanhaeducacao.org.br

${ }^{9}$ Disponível em http://www.campanhaeducacao.org.br/boletim. Acessado em 21 de janeiro de 2007.

${ }^{10}$ Disponível no site da campanha, já citado.

11 Para se ter dimensão da contradição existente no governo Lula, segundo reportagem do Congresso em Foco, de 20 de dezembro de 2006, à medida que os movimentos iam aderindo à tese do Ministério da Educação da edição de uma MP, como forma de regulamentar o FUNDEB, possibilitando sua implementação já em 2007, apressando assim o repasse de verbas para os estados e municípios, o Ministério da Fazenda exigia que a regulamentação ocorresse por meio de Projeto de Lei, como queriam os movimentos organizados que viam no PL a possibilidade de discussão e intervenção maior. O motivo do Ministério da Fazenda, porém, era somente o de adiar o repasse dos recursos. (www.congressoemfoco.com.br acessado em 21 de janeiro de 2007).

${ }^{12}$ Para Davies (2006), entende-se como fundo formal uma reserva de impostos, formalmente definido como tal e vinculado a uma parte do sistema educacional, como o FUNDEF (vinculado ao Ensino Fundamental regular), o FUNDEB (destinando à educação básica) ou, ainda, o Fundo do Ensino Superior, previsto no anteprojeto da reforma do Ensino Superior, proposto pelo governo federal, em dezembro de 2004.

${ }^{13}$ PEC 112/99 disponível em www.pt.org.br 
14 A Emenda Constitucional n ${ }^{\circ}$ 59, promulgada pelo Congresso Nacional em 11 de novembro de 2009, determina o fim gradual DRU sobre os recursos federais para a educação até a extinção do mecanismo, em 2011. Com a emenda, esse percentual cai para $12,5 \%$ no exercício de 2009 e diminuirá para $5 \%$ em 2010. Não haverá mais a incidência a partir de 2011. Assim, serão cerca de R \$ 9 bilhões a mais no orçamento da educação (www.mec.gov.br).

Artigo recebido em: 17/08/09

Aprovado para publicação em: 19/12/09 